\title{
Technology Metals in the Circular Economy of Cities
}

\author{
FISEHA TESFAYE $\left({ }^{1,5},{ }^{1,5}\right.$ JOSEPH HAMUYUNI, ${ }^{2}$ \\ CHUKWUNWIKE O. ILOEJE ${ }^{3}$ and ALEXANDRA E. ANDERSON ${ }^{4}$
}

\begin{abstract}
1.-Johan Gadolin Process Chemistry Centre, Åbo Akademi University, Henrikinkatu 2, FI20500 Turku, Finland. 2.-Metso Outotec Research Center, Kuparitie 10, FI-28101 Pori, Finland. 3.-Energy Systems Division, Argonne National Laboratory, 9700 South Cass Avenue, Lemont, IL 60439-6903, USA. 4.-Gopher Resource, 6505 Jewel Ave, Tampa, FL, USA. 5.—e-mail: fiseha.tesfaye@abo.fi
\end{abstract}

While the demand for technology metals such as precious metals, rare earths, and minor metals $(\mathrm{Sb}$, Co, etc.) will continue to increase, their production from primary sources is challenged by complexity and poor grade. On the other hand, waste streams are emerging as alternative sources of the technology metals with many advantages. However, the current recovery rate of these metals from the waste streams is inadequate. Therefore, promoting efficient recovery of the technology metals from municipal and industrial side streams is vital and facilitates the move towards a circular economy. Thus, innovative recycling technologies, in addition to effective waste management, are essential to enable this transition.

Urban areas are at the forefront of future sources of the technology metals. Urban mining involves collection and management of spent products and preprocessing and recovery of valuable materials, as illustrated in Fig. 1. Recently, some cities in Europe signed the EU Green City Accord, an initiative to make cities greener, cleaner, and healthier. ${ }^{1}$ Technological developments for sustainable and economic recovery of technology metals from municipal waste will eventually help to realize the goals set by the initiative.

In 2020 and 2021, JOM advisors of the Recycling and Environmental Technologies Committee and the Process Technology and Modeling Committee of TMS-The Minerals, Metals \& Materials

Fiseha Tesfaye, Joseph Hamuyuni, Chukwunwike O. Iloeje, and Alexandra E. Anderson are Guest Editors for the Recycling and Environmental Technologies Committee, Energy Committee, and Process Technology and Modeling Committee of TMS and coordinated the topic on Technology Metals in the Circular Economy of Cities in this issue.

(Received November 24, 2021; accepted December 1, 2021; published online January 1, 2022)
Society-organized special topics focusing on improved extractions and recoveries of the strategic metals: "Cleaner Manufacturing of Critical Metals"2 and "Thermodynamic Optimization of Critical Metals Processing and Recovery" ${ }^{3,4}$ For this special topic, original research and review papers focusing on technology metals recycling were invited, and eight papers were selected for publication after a peer review.

The article "A Review on Recycling of End-of-Life Light-Emitting Diodes for Metal Recovery" by Mir et al. provided an overview of relevant recycling processing steps, including physical, hydrometallurgical, and pyrometallurgical treatments. This review presented some insight on the influence of gallium compounds (GaN, GaAs) on recycling strategies and proposed a recycling flowsheet design for the optimal recovery of $\mathrm{Ga}, \mathrm{In}, \mathrm{Au}$, and REEs. The second paper, "Waste Pharmaceutical Blister Packages as a Source of Secondary Aluminum" by Shukla et al., investigated the potential of aluminum recovery from waste pharmaceutical blister packages (WPBs). The authors reported on the separation of aluminum and plastic(s) in WPBs by the delamination technique with a solution of organic solvents. Their experimental studies at different conditions and with different types of WPBs suggested the possibility of recovering 100\% of aluminum from WPBs. This study also presented the flowsheet for recycling and post-processing of segregated aluminum from the plastics.

The paper "The Partitioning Behaviors of $\mathrm{Au}, \mathrm{Ag}$, and $\mathrm{Sn}$ in the $\mathrm{Cu}-\mathrm{FeO}_{\mathrm{X}}-\mathrm{SiO}_{2}-\mathrm{CaO}-\mathrm{Al}_{2} \mathrm{O}_{3}$ Smelting System in the Presence of Halogen Elements" by Liu et al. experimentally examined the influence of halogen elements $\mathrm{F}, \mathrm{Cl}$, and $\mathrm{Br}$ on the distribution behaviors of $\mathrm{Au}, \mathrm{Ag}$, and $\mathrm{Sn}$ in the $\mathrm{Cu}-\mathrm{FeO}_{\mathrm{X}}-\mathrm{SiO}_{2}-$ $\mathrm{CaO}-\mathrm{Al}_{2} \mathrm{O}_{3}$ slag smelting system. They reported on the impact of introducing $\mathrm{CaF}_{2}, \mathrm{CaCl}_{2}$, or $\mathrm{CaBr}_{2}$ on the partitioning of $\mathrm{Au}, \mathrm{Ag}$, and $\mathrm{Sn}$ among metallic 


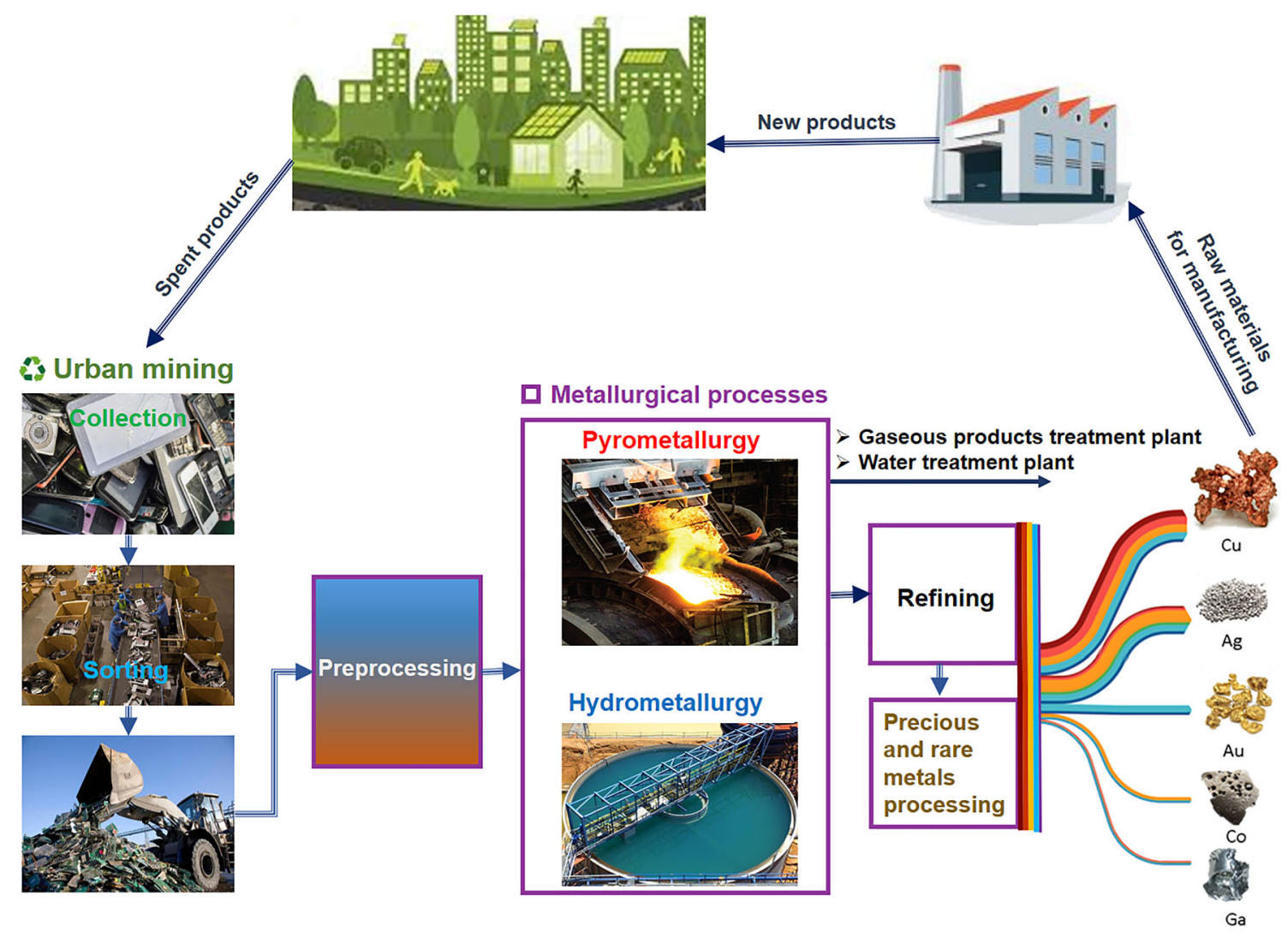

Fig. 1. Schematic representation of the cycles of technology metals through metallurgical processes.

phases, the slag, and the gas phase. The paper titled "An Investigation into the Alkali Metals Removal from Zn-Bearing Dusts Pellets in Direct Reduction" by Wang et al. investigated the direct reduction and removal behavior of alkali metals of carbon-containing Zn-bearing dust pellets, which are typical hazardous solid wastes generated in iron and steel industry. Authors reported a single-step method for both harmful metals removal and the agglomeration of reduced dusts. According to their results, removal rates of potassium and sodium were controlled by reduction reactions of potassium and sodium-bearing phases. For the reduction processes at $1200^{\circ} \mathrm{C}$ for $50 \mathrm{~min}$, they report the reduced pellets with iron grade of $73.42 \%$ and low contents of the alkali metals, which could be directly used as a charge for improving blast furnace operation without further agglomeration. The paper titled "Facile Method for the Cadmium Separation from Zinc and Cadmium Bearing Dust by Zinc Plate Electroreplacement (ZPER) Process" by Liu et al. examined separation of $\mathrm{Cd}$ from $\mathrm{Zn}$ - and Cd-bearing dusts by applying the ZPER process with low consumption of $\mathrm{Zn}$. They reported efficient removal of $\mathrm{Cd}$ from acidic leachate of the dust by zinc plate replacement assisted with a microcurrent and new reaction surface of the zinc plate exposed by electrodissolution, allowing the replacement reaction to proceed. In addition to $\mathrm{Cd}$ removal from acidic leachate of the dust, they investigated Cd removal from a sulfuric acid leaching solution of $\mathrm{Cd}-\mathrm{Zn}$-bearing dust and reported similar results. According to the concluding remark made by the authors, the proposed new ZPER process has advantages of efficient removal of $\mathrm{Cd}$ ( 98\%), low consumption of $\mathrm{Zn}(\sim 1 \%)$, and high economic values.

The last three articles titled "Titanium Extraction from Titania-Bearing Blast Furnace Slag: A Review" by Shi et al., "Equilibrium Phase Relations of $\mathrm{CaO}-\mathrm{SiO}_{2}-\mathrm{Ti}_{3} \mathrm{O}_{5}$ System at $1400{ }^{\circ} \mathrm{C}$ and $\mathrm{p}\left(\mathrm{O}_{2}\right)$ of $10^{-16}$ atm" by Shi et al., and "Experimental Study on the Phase Relations of the $\mathrm{SiO}_{2}-\mathrm{MgO}-\mathrm{TiO}_{2}$ System in Air at $1500{ }^{\circ} \mathrm{C}$ " by Chen et al. presented important data on phase relations in the $\mathrm{TiO}_{2}$-based systems for promoting efficient recovery of $\mathrm{Ti}$ and other technology metals through high-temperature processes.

The peer-reviewed papers in this special topic should be of interest to a broad readership including those contributing to resource security and promoting sustainable production of strategic metals from the municipal and industrial waste streams. The titles of the articles published under this topic in the second JOM issue of 2022 (vol. 74, no. 2) are listed below and can be fully accessed via the journal's page at: https://link.springer.com/journal/11837/74/ 2/page/1.

- "A Review on Recycling of End-of-Life Light- 
Emitting Diodes for Metal Recovery" by S. Mir, A. Vaishampayan, and N. Dhawan.

- "Waste Pharmaceutical Blister Packages as a Source of Secondary Aluminum" by S. Shukla, P. Halli, and M. Lundström.

- "The Partitioning Behaviors of $\mathrm{Au}, \mathrm{Ag}$, and $\mathrm{Sn}$ in the $\mathrm{Cu}-\mathrm{FeO}_{\mathrm{X}}-\mathrm{SiO}_{2}-\mathrm{CaO}-\mathrm{Al}_{2} \mathrm{O}_{3}$ Smelting System in the Presence of Halogen Elements" by Z. Liu, F. Ye, R. Chen, H. Wang, and L. Xia.

- "An Investigation into the Alkali Metals Removal from Zn-Bearing Dusts Pellets in Direct Reduction" by D. Wang, D. Zhu, J. Pan, Z. Guo, C. Yang, X. Wang, and T. Dong.

- "Facile Method for the Cadmium Separation from Zinc and Cadmium Bearing Dust by Zinc Plate Electroreplacement (ZPER) Process" by S. Liu, S. Yang, S. Wang, T. Luo, Y. Chen.

- "Titanium Extraction from Titania-Bearing Blast Furnace Slag: A Review" by J. Shi, Y. Qiu, B. Yu, X. Xie, J. Dong, C. Hou, J. Li, and C. Liu.

- "Equilibrium Phase Relations of $\mathrm{CaO}-\mathrm{SiO}_{2}$ $\mathrm{Ti}_{3} \mathrm{O}_{5}$ System at $1400{ }^{\circ} \mathrm{C}$ and $\mathrm{p}\left(\mathrm{O}_{2}\right)$ of $10^{-16}$ atm” by J. Shi, Y. Qiu, X. Wan, B. Yu, M. Chen, F. Zhao, J. Li, C. Liu, and P. Taskinen.

- "Experimental Study on the Phase Relations of the $\mathrm{SiO}_{2}-\mathrm{MgO}-\mathrm{TiO}_{2}$ System in Air at $1500{ }^{\circ} \mathrm{C}$ " by M. Chen, X. Wan, J. Shi, P. Taskinen, and A. Jokilaakso.

\section{ACKNOWLEDGMENTS}

Organizers of this topic sincerely thank all authors and reviewers that have contributed to the successful publication of this special issue. We are convinced that your expertise has resulted in an excellent issue on this timely topic of JOM. The authors are also grateful to the Academy of Finland (decision number 311537) and the CircVol 6Aika project for financial support as part of the activities of the Johan Gadolin Process Chemistry Centre at
Åbo Akademi University. We acknowledge support from UChicago Argonne LLC, Operator of Argonne National Laboratory ("Argonne"). Argonne National Laboratory's work was supported by the US Department of Energy, Office of Energy Efficiency and Renewable Energy (EERE), under contract DEAC02-06CH11357. The US Government retains for itself, and others acting on its behalf, a paid-up nonexclusive, irrevocable worldwide license in said article to reproduce, prepare derivative works, distribute copies to the public, and perform publicly and display publicly, by or on behalf of the Government. The Department of Energy will provide public access to these results of federally sponsored research in accordance with the DOE Public Access Plan at https://www.energy.gov/down loads/doe-public-accessplan

\section{FUNDING}

Luonnontieteiden ja Tekniikan Tutkimuksen Toimikunta, 311537, Fiseha Tesfaye.

\section{CONFLICT OF INTEREST}

On behalf of all authors, the corresponding author states that there are no conflicts of interest.

\section{REFERENCES}

1. EUROCITIES, The Green City Accord: a new EU initiative for greener, healthier cities. https://eurocities.eu/latest/the-g reen-city-accord-a-new-eu-initiative-for-greener-healthier-cit ies/. Accessed 31 Oct 2021.

2. F. Tesfaye, N. Ma, and M. Zhang, JOM 72, 764. https://doi. org/10.1007/s11837-019-03976-w (2020).

3. C.O. Iloeje, F. Tesfaye, and A.E. Anderson, JOM 73, 665. h ttps://doi.org/10.1007/s11837-020-04534-5 (2021).

4. C.O. Iloeje, F. Tesfaye, and A.E. Anderson, JOM 73, 862. h ttps://doi.org/10.1007/s11837-020-04561-2 (2021).

Publisher's Note Springer Nature remains neutral with regard to jurisdictional claims in published maps and institutional affiliations. 